\title{
Evaluation of a pen injector system for growth hormone treatment
}

\author{
Peter D Gluckman, Wayne S Cutfield
}

\begin{abstract}
The increasing use of human growth hormone (hGH) treatment has resulted in the introduction of a number of alternative delivery systems to conventional syringe and needle administration. We examined patients' evaluation of a new delivery system, the Kabipen (KabiVitrum). We also assessed the accuracy of hGH delivery by the Kabipen. Of the 77 survey respondents 13 had used only the Kabipen, 14 the syringe only, and 50 had used both systems. Altogether $46(92 \%)$ of those who had used both systems preferred the Kabipen. Children over 10 years were more likely to self administer hGH with the Kabipen (64\%) than syringe $(25 \%)$. Patient instructions, convenience of use, and comfort of use were rated better for the Kabipen than syringe. With a dose setting of 2 units the Kabipen delivered a mean (SD) of $1.997(0.073)$ units with $102.5 \%$ recovery from a unit cartridge. In summary the Kabipen is an accurate device clearly preferred by the majority of hGH recipients surveyed.
\end{abstract}

Clinicians prescribing human growth hormone (hGH) are aware of the problems that limit the acceptance of this form of treatment by many families. Recent studies have unequivocally shown the value of daily rather than traditional injections three times a week. ${ }^{12}$ With the rapid increase in utilisation of $\mathrm{hGH}$ as a result of its wider availability alternative delivery systems have been developed to facilitate ease of administration.

The traditional form of $\mathrm{hGH}$ formulation has been a single dose vial, which had to be reconstituted with diluent for each injection. More recently multiple dose vials have been developed in which several doses can be drawn into syringes from a single reconstituted vial. Most recently a device originally developed for insulin administration, the pocket injector pen, ${ }^{3}$ has been applied to hGH treatment. Although some hGH injector pens still require reconstitution of the powdered formulation in vials and transfer to the injector unit, others utilise specific vials for the injector device and thus minimise patient involvement and error in preparing the formulation. New Zealand was the first country to licence a pen for hGH treatment and the purpose of this paper is to review our experience. We report on the results of a blinded questionnaire of patients and their families which compared the injector pen with conventional syringe administration. We also report on the accuracy and economy of the injector pen relative to earlier formulations.

\section{Methods}

At the time of this survey, all patients received one of three formulations (Genotropin, KabiVitrum, Stockholm) of recombinant hGH: 4 unit single dose vials, 12 unit multiple dose vials, or the Kabipen (KábiVitrum) system. The latter consists of an injector pen into which is inserted a 16 unit cartridge of recombinant hGH. The powdered hormone and diluent within the cartridge are in separate compartments. Automatic mixing occurs with insertion of the cartridge into the pen which is then available for multiple and variable (0.5-4 units) dose selection over several days without further preparation. The pen was licenced in New Zealand in June 1989.

The survey evaluating modes of hGH treatment was conducted in April 1990. Of the 105 children on the hGH treatment register, questionnaires were sent to 96 with current addresses.

Anonymous questionnaires were completed by the parent in conjunction with the subject receiving $\mathrm{hGH}$. The questionnaire complied with the guidelines of the human subjects research ethical committee of the University of Auckland.

The questionnaire evaluated the respondent's perception of: the benefits of the injector pen compared with conventional syringe based hGH treatment, the adequacy of patient/family instruction on use of hGH administration, satisfaction regarding information provided on the growth disorder, and on the response to treatment.

Subject preference with explanation was requested of those who had used both systems. Subjects were asked to rate the quality of instructions provided, the convenience of use, and the comfort of use for each type of delivery system they had used. The subject was also asked to comment on whether the system could be improved and to detail technical or practical problems with the device. Qualitative scales were also used to rate satisfaction with the clinical service provided.

Both of the authors randomly and independently evaluated the accuracy of the hormone delivery systems. A random selection of pens was used to deliver eight doses of 2 units each into preweighed vials. The needle was replaced after each dose. The manufacturer's instructions for priming and delivery were followed 
exactly. By weighing the vial before and after priming and at the end of the delivery of the eighth dose the actual delivery from a 16 unit vial was assessed. Similarly the accuracy and recovery from 12 unit vials was carefully assessed by the authors using $1 \mathrm{ml}$ B-D plastipak syringes (Becton-Dickinson) with microfine III needles. The syringe and needle were replaced after every second dose.

\section{DATA ANALYSIS}

Statistical analysis was by non-parametric techniques as the ratings used a ordinal not interval scale. The Mann-Whitney test was used for two sample comparison, the Kruskal-Wallis test for oneway analysis of variance, and the Wilcoxon matched pair signed rank test for paired data; $\chi^{2}$ analysis was used for frequency distribution analysis.

\section{Results}

Of 80 returned questionnaires three were excluded from the analysis: one had discontinued treatment, one had yet to start, and one return was incomplete. The analysis is based on a $83 \%$ response rate.

Fifty respondents had used both the syringe and injector pen system. Fourteen had used only a syringe system and of these nine were currently using a multiple dose vial and five were using the 4 unit vial. Thirteen had used only the injector pen-the latter were those most recently placed on hGH treatment.

The hormone was self administered in 35 subjects and by a parent for the remaining subjects except for one infant where the hormone was administered by a visiting nurse. When the analysis was restricted to children 10 years or older, self administration was far more likely using the injector pen $(64 \%)$ than the syringe $(25 \%, \mathrm{p}<0.04)$ (table 1$)$.

The most useful sources of patient education with regard to hGH administration were clearly the clinic nurse and/or videotaped administration demonstration ( $67 \%$ of respondents). Other health professionals $(9 \%)$, pharmaceutical representatives $(8 \%)$, doctors $(7 \%)$, and written material $(4 \%)$ played only a minor role.

There were appreciable differences when patient evaluation of the injector pen and syringe delivery systems were compared (table 2 ). Of the 50 respondents who had used both delivery systems, $92 \%$ indicated a preference for the injector pen. The quality of instructions $(p<0.01)$, the convenience of use $(p<0.01)$, and the comfort of use $(p<0.01)$ were rated significantly better for the injector pen than for the syringe systems (table 2). When the small

Table 1 Administration of $h G H$

\begin{tabular}{|c|c|c|c|c|}
\hline & \multicolumn{2}{|c|}{ Total study $(n=77)$} & \multicolumn{2}{|c|}{$\begin{array}{l}\text { Subjects } \\
(n=55)^{*}\end{array} 10$ years } \\
\hline & Pen users & $\begin{array}{l}\text { Syringe } \\
\text { users }\end{array}$ & Pen users & $\begin{array}{l}\text { Syringe } \\
\text { users }\end{array}$ \\
\hline $\begin{array}{l}\text { Subject } \\
\text { Care giver }\end{array}$ & $\begin{array}{l}31 \\
32\end{array}$ & $\begin{array}{r}4 \\
10\end{array}$ & $\begin{array}{l}30 \\
17\end{array}$ & $\begin{array}{l}2 \\
6\end{array}$ \\
\hline
\end{tabular}

Table 2 Comparison of both systems by respondents who used both (mean score, ${ }^{*} n=50$ )

\begin{tabular}{llll}
\hline & Pen & Syringe & $p$ Valuet \\
\hline Quality of instructions & 1.5 & 2.3 & $<0.01$ \\
Convenience of use & 1.3 & 3.3 & $<0.01$ \\
Comfort of use & 2.2 & 3.5 & $<0.01$
\end{tabular}

*A 1-5 rating system was used with 1 indicating the mos

favourable response.
† Mann-Whitney test.

Table 3 Accuracy of 2 unit delivery

\begin{tabular}{lll}
\hline & $\begin{array}{l}\text { Kabipen } \\
(n=35) t\end{array}$ & $\begin{array}{l}\text { Genotropin* } \\
12 \text { unit vial } \\
(n=18) t\end{array}$ \\
\hline Mean (SD) (units) & $1.997(0.073)$ & $2.000(0.067)$ \\
Coefficient of variation (\%) & 3.35 & 3.33 \\
Experimental range (units) & $1.87-2.08$ & $1.82-2.06$ \\
\hline $\begin{array}{l}{ }^{*} \text { Delivered by B-D plastipak } 1 \mathrm{ml} \text { syringe and microfine III } \\
\text { needle. } \\
\text { †Number of doses weighed. }\end{array}$
\end{tabular}

number of respondents who had used only the pen $(n=13)$ or syringe $(n=14)$ were compared, there were no differences in patient evaluation.

Of the 63 injector pen users, 13 had minor problems in the initial month of use solved by further training. Eleven pens were replaced because of mechanical problems; however of these nine were from the first production batch and occurred in the first months after licensing. Subsequently mechanical problems have not been encountered. Only two subjects had switched back to a syringe system, both because they found the pen heavy to use and had been on a syringe system for some years previously.

The injector pen and syringe systems are of comparable accuracy with the coefficient of variation for the delivery of a 2 unit dose being $3.5 \%$ and $3.3 \%$ respectively (table 3 ). The recovered hormone from a vial averaged $102 \cdot 5 \%$ in the pen system and $100 \%$ for the 12 unit vial system.

\section{Discussion}

Relatively little consideration has been given to the patient perspective for hGH treatment. Historically this reflects the fact that until recently restrictions on hGH supply and the generally non-commercial origin of the hormone meant that there was little motivation to consider these apsects. However the use of hGH has increased considerably after the introduction in 1985 of commercially produced recombinant $\mathrm{hGH} .^{4-8}$ The range of indications continues to broaden and it is now generally accepted that daily injections are the minimum frequency for an optimal growth response. ${ }^{9}$ It is now evident that hGH should be prescribed in relation to body size rather than as the traditional fixed dose regimen of 4 units three times a week. ${ }^{1011}$ Consequently, the need for administration systems that allow for individualised daily dose schedules has become important to avoid wastage from either excessive hormone administration or incomplete vial usage. The multiple dose vial systems achieve that purpose, but do not greatly alter the convenience for the patient or care giver, except for the reduced frequency of vial preparation. 
The child on hGH treatment is faced with daily injections for a number of years. Given the need to maintain sterility and for appropriate storage of the hormone and diluent vials, there are a number of practical inconveniences associated with classical formulations of hGH. These are perceived by many families as intrusive on their life styles. In addition the problems arising from the use of syringes and needles appear somewhat complex to families-this is seen in the present study among children 10 years or older who are far more likely to self administer hGH by Kabipen than syringe (table 1).

Little consideration has been previously given to the patient's attitudes in the choice of hGH delivery systems. We assessed in blind fashion the responses of 50 families who had experienced a syringe system before use of the injector pen. Most (92\%) preferred the injector pen primarily because of the greater convenience. This included the considerably less time needed each day for hormone administration, the less complex preparation, the greater freedom to travel with less equipment, and a greater 'sense of independence'. These advantages were reflected in the increased frequency of self administration among pen users. Such autonomy facilitates the adaptation of the child to his/her treatment programme. Several families also expressed the concern that syringes and needles stored in the house could be taken and used for illicit drug use. The pen was also considered to be significantly more comfortable to use, although only a few (8\%) gave this increased comfort as the primary reason for preferring the pen.

The reasons given by the small subgroup $(8 \%)$ of subjects who preferred the syringe system principally included dissatisfaction regarding pen administration instruction and lack of information on and/or disappointment with growth progress. These concerns appear to be a reflection of inadequate information rather than any technical benefits that the syringe system had to the injector pen.

Very similar scores were given for the injector pen by those who had only used the injector pen and those who had used both systems. However, those who had used only the syringe systems tended to rate the syringe based systems better than those who had experience of both, reflecting that this was a group of older and longer treated patients, who had generally been reluctant to change systems and were generally satisfied with their management.

No difference in accuracy or recovery was observed between the two systems. However, the handling of the vial is minimal for the injector pen system assessed in this study. In con- trast the handling of any syringe system will involve greater risk of error and of hormone loss or contamination. However, it should be noted that not all injector pen systems are equivalent. At least two other systems are marketed which require extensive handling of the hormone by the patient as the vial is not preloaded. As accuracy of dose delivery, hormone recovery, and cost are all equivalent in the systems we evaluated then the major consideration in the choice of a delivery system must be patient comfort. The present study clearly demonstrates patient preference for the injector pen delivery system.

The survey also clearly shows that the most successful way to educate patients and their families is to use a clinic nurse educator and/or a videotape.

In summary the Kabipen is an injector device that accurately delivers the dose set without any wastage from a 16 unit cartridge. When compared with syringe administration the Kabipen was clearly preferred by the majority of patients and was more likely to result in self administration in older children.

This work was funded in part by the Medical Research Council of New Zealand. We thank Ms Karen Tailuga and Vanessa Cox fo their assistance.

1 Albertsson-Wikland K, Westphat O, Westgren U. Daily subcutaneous administration of human growth hormone in growth hormone deficient children. Acta Paediatr Scand 1986;75:89-97.

2 Kastrup KW, Sandahl Christiansen J, Koch Anderson J Orskov $\mathrm{H}$. Increased growth rate following transfer to daily s.c. administration from three weekly i.m. injections of $\mathrm{hGH}$ in growth hormone deficient children. Acta Endo crinol (Copenh) 1983;104:148-52.

3 Saubrey N, Arnold-Larsen S, Moller-Jensen B, Kuhl C. Comparison of continuous subcutaneous insulin infusion with multiple insulin injections using the novopen. Diabetic Medicine 1988;5:150-3.

4 Rosenfeld RG, Hintz RL, Johanson AJ, et al. Three year results of a randomised prospective trial of methionyl human growth hormone and oxandrolone in Turner syndrome. $\mathcal{F}$ Pediatr 1988;113:393-400.

5 Takano K, Shizume K, Hibi I. Turner syndrome: treatment of 203 patients with recombinant human growth hormone of 203 patients with recombinant human growth hormone
for one year. Acta Endocrinol (Copenh) 1989;120:559-68.

6 Wit JM, Fokker MH, de Muinck Keizer Schrama SM, et al. Effects of two years of methionyl growth hormone therapy in two dosage regimens in prepubertal children with shor stature, subnormal growth rate and normal growth hormone response to secretagogues. I Pediatr 1989;115 $720-5$.

7 Koch VH, Lippe BM, Nelson PA, Boechat MI, Sherman $B M$, Fine RN. Accelerated growth after recombinan human growth hormone treatment of children with chronic renal failure. $\mathcal{f}$ Pediatr 1989;115:365-71.

8 Stanhope R, Ackland F, Hamill G, Clayton J. Physiological growth hormone secretion and response to growth hormone treatment in children with short stature and intrauterine growth retardation. Acta Paediatr Scand [Suppl] 1989;349: growth

9 Smith PJ, Hindmarsh PC, Brook CG. Contribution of dose and frequency of administration to the therapeutic effect of and frequency of administration to the therapeutic effec
growth hormone. Arch Dis Child 1988;63:491-4.

10 Preece MA, Tanner JM, Whitehouse RH, Cameron N. Dose dependence of growth response to human growth hormone in growth hormone deficiency. F Clin Endocrinol Meta 1975;42:477-83.

11 Frasier SD, Costin G, Lippe BM, Aceto T, Bunger PF. Dose response curve for human growth hormone. $\mathcal{F}$ Clin Endocrinol Metab 1981;53:1213-7. 